\title{
Wikipedia Edit-a-thons as Sites of Public Pedagogy
}

\author{
LAURA MARCH and SAYAMINDU DASGUPTA, University of North Carolina at Chapel Hill, USA
}

\begin{abstract}
Wikipedia edit-a-thon events provide a targeted approach toward incorporating new knowledge into the online encyclopedia while also offering pathways toward new editor participation. Through the analysis of interviews with 13 edit-a-thon facilitators, however, we find motivations for running edit-a-thons extend far beyond adding content and editors. In this paper, we uncover how a range of personal and institutional values inspire these event facilitators toward fulfilling broader goals including fostering information literacy and establishing community relationships outside of Wikipedia. Along with reporting motivations, values, and goals, we also describe strategies facilitators adopt in their practice. Next, we discuss challenges faced by facilitators as they organize edit-a-thons. We situate our findings within two complementary theoretical lenses-information ecologies and public pedagogy-to guide our interpretation. Finally, we suggest new ways in which edit-a-thons, as well as similar peer production events and communities, can be understood, studied, and evaluated.
\end{abstract}

CCS Concepts: • Human-centered computing $\rightarrow$ Empirical studies in collaborative and social computing; Empirical studies in HCI; • Applied computing $\rightarrow$ Collaborative learning.

Additional Key Words and Phrases: edit-a-thons, facilitation, public pedagogy, information ecologies, Wikipedia, librarianship

ACM Reference Format:

Laura March and Sayamindu Dasgupta. 2020. Wikipedia Edit-a-thons as Sites of Public Pedagogy. Proc. ACM Hum.-Comput. Interact. 4, CSCW2, Article 100 (October 2020), 26 pages. https://doi.org/10.1145/3415171

\section{INTRODUCTION}

Online peer production communities such as Wikipedia, where community members collaboratively organize knowledge production, see declines in the number of contributors over time [23, 53]. One strategy members of the Wikipedia community use to combat this attrition is organizing and supporting edit-a-thon events. Wikipedia edit-a-thons are locally organized meet-up events designed to encourage and support editors to add new content to the online encyclopedia. Edita-thons are also used to introduce new editors to Wikipedia by providing technical training, reference instruction, and other content guidance. Increasingly, a number of edit-a-thons are also organized with the specific goal of addressing existing biases and gap within Wikipedia, often by explicitly encouraging content creation on or about underrepresented people or topics. Scholars have previously studied these events using a variety of frames such as supportive learning environments (e.g., [29]), a successful event for recruitment and retention of newcomers (e.g., [15]), and as a strategy to address and organize around biases and gaps in Wikipedia (e.g., [14, 62]).

Edit-a-thons provide a rich area of study for CSCW and human-computer interaction (HCI) research for two primary reasons. First, edit-a-thon events offer local, physical gatherings intended

Authors' address: Laura March, lmarch@unc.edu; Sayamindu Dasgupta, sayamindu@unc.edu, University of North Carolina at Chapel Hill, School of Library and Information Science, Chapel Hill, North Carolina, 27599-3360, USA.

Permission to make digital or hard copies of all or part of this work for personal or classroom use is granted without fee provided that copies are not made or distributed for profit or commercial advantage and that copies bear this notice and the full citation on the first page. Copyrights for components of this work owned by others than the author(s) must be honored. Abstracting with credit is permitted. To copy otherwise, or republish, to post on servers or to redistribute to lists, requires prior specific permission and/or a fee. Request permissions from permissions@acm.org.

(C) 2020 Copyright held by the owner/author(s). Publication rights licensed to ACM.

2573-0142/2020/10-ART100 \$15.00

https://doi.org/10.1145/3415171

Proc. ACM Hum.-Comput. Interact., Vol. 4, No. CSCW2, Article 100. Publication date: October 2020. 
to connect participants to one another as well as bolster a larger online peer production community. Thus, lessons drawn from studies of edit-a-thons can inform the design and evaluation of other offline events intended to support peer production focused communities [11, 41, 54]. Second, a significant proportion of edit-a-thon events are organized with an explicit goal toward addressing existing gaps and biases in Wikipedia. For example, the global series of edit-a-thons organized by the Art + Feminism organization ${ }^{1}$ are aimed at addressing "the information gap about gender, feminism, and the arts on the internet" by closing "gaps in content and editorial representation on Wikipedia." These gaps and biases impact much more than the online encyclopedia itself. Increasingly, other digital platforms and products are using Wikipedia content due to its Free and Open nature, thereby inheriting its problems. As online companies with billions of users such as Google and Facebook make more use of Wikipedia content directly (e.g., in search results), or indirectly (e.g., using the text corpus of Wikipedia to train artificial intelligence models), biases in Wikipedia show up in the technologies of these companies. Edit-a-thons represent a potent strategy to address this issue-hence an understanding of the dynamics and drivers of edit-a-thons becomes not only an exercise in understanding how to combat bias in Wikipedia, but also in broader technical systems that make use of Wikipedia content.

The tasks of organizing edit-a-thons, including planning, advertising, and facilitating, are often carried out by local volunteer facilitators who may or may not have strong connections to the broader Wikipedia community. While most existing academic work on edit-a-thons examine the participants and/or the outcomes of these events, in this paper, we focus on facilitators-specifically their motivations, strategies, and challenges. We interviewed 13 edit-a-thon facilitators from across the United States and found motivations for running edit-a-thons extend beyond supporting edits and cultivating new Wikipedia editors. We uncover that these facilitators are driven by a range of personal and institutional values toward broader goals, including fostering information literacy, facilitating public engagement with cultural institutions, and establishing community relationships outside of Wikipedia. In addition to these motivating factors and goals, we also find facilitators use a number of pedagogical strategies to run the events, such as managing expectations of participants, taking advantage of the event's locale, using the physical nature of the events to foster social connections, and leveraging connections with established Wikipedia community members, to ensure successful outcomes for their edit-a-thons. Finally, we identify a number of challenges faced by facilitators while they work toward accomplishing their edit-a-thon goals, many of which are rooted in systemic biases and issues present within the larger Wikipedia community. We situate these findings using two complementary theoretical frames-information ecologies [37] and public pedagogy $[19,48]$-to help interpret the nature and evolution of edit-a-thons. Our findings and analyses present a more complex picture of edit-a-thons. These events are not simply about editing nor truly about Wikipedia, thus pointing to the need for new ways of understanding, studying, and evaluating edit-a-thons. We use the two theoretical frames to suggest how our findings can be applied to Wikipedia as well as similar events that connect to other online peer production communities.

The paper is structured as follows: we present a background $(\S 2)$ where we describe the empirical context of edit-a-thons and relevant scholarly work. In this section, we also briefly describe the theoretical constructs we use to understand and situate our findings. Next, we describe our research methods and our participants (§ 3$)$ before presenting our findings in the subsequent section (§ 4$)$. We then discuss $(\S 5)$ our findings using information ecologies and public pedagogy; these theories provide complementary frames for understanding the phenomenon of edit-a-thons and how they emerge and evolve. We then employ these two theoretical framings to propose new and expanded

$\overline{{ }^{1} \text { https://www.artandfeminism.org/ }}$ 
ways in which edit-a-thons and similar events can be understood, studied, and evaluated. Finally, we reflect on our findings ( $(6)$ before concluding with an explicit reiteration of the implications of our work, not just within the context of Wikipedia, but for broader work around peer-production and digital cultures (§ 7).

The key contributions of this paper are (i) an empirical account of the motivations of the volunteers who organize and facilitate edit-a-thons, the strategies they employ and the challenges they face, (ii) a theory-driven interpretation-grounded in our findings-of what edit-a-thons are and how they emerge and evolve, and (iii) lessons regarding the nature of edit-a-thons which seek to reshape how edit-a-thons as well as similar offline events in the service of other online peer-production communities are evaluated and understood from research and policy perspectives.

\section{BACKGROUND}

In this section, we describe the empirical context for our study, related scholarly work, and the theoretical constructs we use to interpret our findings.

\subsection{Empirical context: Wikipedia edit-a-thons}

An edit-a-thon, a portmanteau of the words "edit" and "marathon," is an event organized by facilitators to edit and improve content on Wikipedia and typically includes training and support for new editors. While the idea was first proposed in 2004, the Wikimedia Foundation (the non-profit that hosts Wikipedia) cited the British Library as the first to use of the word "edit-a-thon" to describe their event in January 2011 [59]. In a study of 121 edit-a-thons held between September 2013 and December 2014 across the world, the Wikimedia Foundation found "the average edit-a-thon had 14 participants, 20,812 characters added or removed, and 7 articles created or improved" [59, p. 2]. These events are social activities in which participants engage with other people and artefacts (both on- and off-line) similar to the methods of conventional writers and reporters [29]. Edit-a-thons are usually organized locally by volunteers, though funding might occasionally come from the Wikimedia foundation in the form of grants.

Much of the available scholarly work on edit-a-thon events are case studies. Edit-a-thons are framed as ways museums, universities, and cultural institutions can supplement communityoriented programming $[14,44,50]$. While edit-a-thons are not required to be organized around a central theme, the series of Art+Feminism edit-a-thons became an extremely popular and wellstudied annual event since its beginning in 2014. By 2015, Art+Feminism edit-a-thons attracted as many participants worldwide as the edit-a-thon event held at the annual Wikipedia community conference, Wikimania [14]. Data collected in 2016 showed 9\% of newcomers who joined Wikipedia as part of an Art+Feminism event continued editing on the site a week after the event, versus just $1 \%$ of newcomers who joined on the same day without being part of an edit-a-thon event [15, p. 30]. Reflecting on the evolution of the relationship between libraries and Wikipedia, Phetteplace [44] argues that while librarians have been wary of Wikipedia in the past, hosting events like Art+Feminism is what libraries and similar institutions ought to be doing to combat prejudices. On the other hand, it has been argued that feminist edit-a-thons can be viewed as asking women to perform additional affective labor as well as spending time "justifying why their efforts are necessary in the first place... women are doing the work of 'editing diversity in' while the structural sexism embedded into the norms and practices of Wikipedia remains the same" [30, p. 11].

Prior scholarly work has often framed edit-a-thons as learning environments. For example, Littlejohn et al. [29] used Tynjälä's[55] Integrative Pedagogies model to describe how Wikipedia edit-a-thons become learning environments through fostering conceptual knowledge, procedural knowledge, and self-regulated knowledge. Two broad intentions underpin edit-a-thons events: 
participant contributions via creating or editing content and the support of people in developing the knowledge and expertise required of Wikipedia editors [29, p. 3]. These experiential learning events shape engagement without predefined learning outcomes, where participants develop greater knowledge of Wikipedia and a more robust understanding of the structural inequalities and bias as related to the site [25, p. 12].

\subsection{Key theoretical concepts: Information ecologies and public pedagogy}

In this paper, we use two key theoretical concepts to interpret the phenomenon of the edit-athon as they emerge in our findings. First ( 5.1 ), we posit that edit-a-thons can be seen as an instance of information ecologies by showing how these events share several characteristic features of information ecologies as theorized by Nardi and O'Day [37]. The notion of an information ecology - "a system of people, practices, values, and technologies in a particular local environment" where "the spotlight [...] is on human activities that are served by technology" (p. 49)-has been utilized and critiqued in CSCW and broader HCI literature [3, 4, 12, 31, 46]. We build on existing critique by suggesting a complementary framing for edit-a-thons, which includes questions of power and cultural politics.

In this second framing (§ 5.2), we connect our findings with public pedagogy [19,48], a concept from education research that has been described in one definition as a "mode of cultural criticism that is essential for questioning the conditions under which knowledge is produced" [18, p. 342]. Public pedagogy has recently seen some engagement in HCI work [38]. While the concept has a long and complex history as a theoretical construct [47], we primarily focus on its relation to cultural politics [18] in order to illustrate, using our data, how the pedagogical actions by edit-a-thon facilitators promote recognizing, questioning, and addressing biases in the culture of Wikipedia and online peer production communities more generally.

\section{RESEARCH DESIGN}

We began with the following broad and interrelated questions:

(1) What motivates facilitators to organize and run Wikipedia edit-a-thons?

(2) What approaches and strategies do facilitators use for organizing and running edit-a-thons?

(3) What challenges do facilitators encounter as they organize and run edit-a-thons and how do they navigate them?

To respond to these questions, we recruited and conducted semi-structured interviews with edit-a-thon facilitators as well as reviewed related publicly available materials (e.g., press reports on edit-a-thons) to better contextualize our findings. Our approach was driven by our desire to develop an understanding of the facilitators' perspectives of edit-a-thons and how they situated the events and participants within the larger Wikipedia community.

\subsection{Participant recruitment}

Thirteen edit-a-thon facilitators participated in semi-structured interviews for this study. As this study focuses on publicly visible work by participants, following past work in HCI research methods [6] and prior CSCW work [16], we asked each participant whether they would prefer us to use a pseudonym to refer to them or their real names, in recognition of the work that they have done. As part of the consent process before the interviewer started to record each conversation, participants provided their preferred gender pronouns and either chose a pseudonym or, if desired, gave permission to use their real names in recognition of the work they have accomplished [6] Nine interviewees preferred she/her pronouns, three preferred he/him pronouns, and one preferred they/their pronouns. All participants chose to use their real names. At the time of hosting their 
most recent edit-a-thon event, six were university librarians, two were public librarians, two were Wikimedians who facilitated edit-a-thons as a major part of their paid or volunteer responsibilities, one was a university archivist, one was a student in a Master of Library Science program, and one worked for the Wikimedia Foundation.

Participants were recruited using snowball sampling, which provided additional information on both social knowledge and power relations [40, p. 329]. The networks uncovered through this sampling technique helped identify noteworthy connections between facilitators themselves, interactions with the Wikimedia Foundation, and other support systems. While asking interviewees to refer other facilitators may have yielded a greater risk of convenience sampling, it allowed the researchers to access, utilize, and study the unique relationships between edit-a-thon facilitators and provided additional insights into edit-a-thons and how they function within a larger social context.

\subsection{Data analysis}

We followed an iterative inductive process for our data analysis based on Braun and Clarke's approach for conducting thematic analysis [5]. Participants were asked to share their experiences as edit-a-thon facilitators in semi-structured interviews with the first author either in-person or through online video conferencing. Interviews ranged from 28-63 minutes (with an average duration of 48 minutes) and included open-ended questions, which allowed the researchers to consider themes as they emerged organically. After each interview, the first author transcribed responses and wrote notes. These notes and discussion about them with the second author informed later interviews as well as the creation of tentative codes. Tentative codes included terms such as "Hacks," "In-Person Interactions," and "Challenges." After later interviews, and further discussions with the second author, the first author drafted memos with focused coding toward developing conceptual categories, sharpened comparisons, and contextualized experiences into larger themes. For example, the tentative code "Hacks" evolved into the further contextualized themes, "Strategies" and "Workarounds." Additional related data (including online dashboard pages and press clippings) were collected to provide further contextual information for events.

\section{FINDINGS}

In this section, we report our findings in the order of our broad driving questions on facilitator motivations, strategies, and challenges. Findings are organized according to themes we found during our analysis within each subsection. Some of the quotes in this section have been lightly edited for readability and clarity, while taking care to ensure that the original, intended meaning is not lost $[9,28]$.

\subsection{Facilitator motivations}

A set of interrelated factors motivated facilitators to host edit-a-thons. Most notably, these include promoting their own values and the values of the institutions they were affiliated with, helping others understand Wikipedia, building connections beyond Wikipedia in local communities, fostering foundational information literacies, and investing in their own professional development. Some of these factors (such as values and professional development) echo motivations that have been found in prior scholarly work to drive contributors to Wikipedia [39].

4.1.1 Personal and institutional values. We found many participants credited their personal values as reasons why they incorporated facilitating edit-a-thons into their professional work. For example, Emily stated edit-a-thons fulfill her personal obligation to help magnify marginalized voices and combat white supremacy: 
It does become daunting-especially for members of identity-based groups who keep getting excluded and turned down-to keep trying, to bang your head against that wall. As someone who can continue to do that, and have it not be personally traumatic, I feel an obligation to do it.

Similarly, Kim and Paul's commitment to diversity and social justice aligns with encouraging new Wikipedia editors, as edit-a-thons inspire people underrepresented among Wikipedia editors to contribute content. Kim shared:

As an information professional and as a woman, I believe in social justice. And while this is seemingly an unrelated component of social justice work, I believe it is still working in the social justice realm because [edit-a-thons encourage] different perspectives, experiences, people, and events. All of these will be missing from Wikipedia without having different people at the table, or at the keyboard, as it were.

Frank attributed his alignment with free and open culture as a catalyst to becoming involved with Wikipedia:

I was involved in open source and free cultural movements before getting involved with Wikipedia-working on those types of ideals, making cultural resources freely available for people to iterate on and innovate.

We also found that beyond personally held values, another motivational driver was the set of values held by institutions with whom the facilitators were affiliated. Given the makeup of our interviewee pool, many of these alignments in values reflected aspirations shared between Wikipedia and libraries, such as connecting people with information that they need, and operating as not-for-profit organizations. Emily described:

The more I spent time with it, the more I realized there's overlapping values between what Wikipedia does and what librarians do. We are both organizations that are invested in connecting people with the information that they need.

Kim outlined four related qualitative outcomes shared by Wikipedia and public libraries: teaching information literacy, partnerships with other community institutions, sharing library collections normally hidden, and "moving the needle on editor demographics." Meg stated she values edit-athons especially when they are in a "setting in which anybody feels welcome," as one would in a public library, which "reinforces the importance of lifelong learning, which is something I really value as well."

Another point raised by Therese related to the shared value of open access:

Libraries love open access. And that's what Wikipedia is.

These statements surface an interconnected mesh of motivating values ranging from personal to institutional. An important notion to consider within this frame is the potential lack of clear distinctions between personal, professional, and institutional values. While institutional values are often shared by affiliates of that institution, these similarities of values may extend beyond specific organizations as well. For example, Frank's alignment with free/open culture is echoed by Therese's articulation of open access being a central value for libraries.

4.1.2 Engage in understanding Wikipedia. In addition to values, a number of facilitators interviewed saw edit-a-thons as a way toward fostering a better understanding of Wikipedia more generally. This understanding ranged from being informed about Wikipedia, to having a critical understanding of how content is produced in Wikipedia, to securing advocates for Wikipedia. In one example, Merrilee stated her "number one goal" of edit-a-thons is ensuring participants feel "better informed about how Wikipedia works" and added, "I don't care how many edits people wind up doing over 
time." She also noted the term edit-a-thon may no longer be appropriate and described how she created new "pop up edit events" at breaks in conferences or other spaces she announces via social media. Merrilee explained:

I don't care how many edits people wind up doing over time. If they've attended an edit-a-thon, and they know how Wikipedia works, and they wind up explaining that to somebody else [...] that's actually the most important shift to me, rather than the mechanics of, "I can edit Wikipedia." It's worthwhile shifting our expectations about what edit-a-thons are supposed to do. Even the term edit-a-thon is a little problematicif people don't wind up editing, they may feel [disappointed] because it's framed so much around editing. [... ] I've even done things I call a pop-up editing event. If I attend a professional conference and there's a substantial break in the conference, I'll say on social media, "I'm going to be in the hotel lobby for these two hours editing Wikipedia and I'm happy to answer any of your editing questions or help you with any problems you've been having with editing."

Facilitators also saw events as opportunities to both foster and address participants' critical views of Wikipedia. Therese specifically used criticisms as teachable moments and encouraged participants who don't trust information on Wikipedia to "go and research it more and find out what might need to be changed." Another example of this was Merrilee's conversation with a man whose wife's page was vandalized (someone replaced all of the times "librarian" with "blanket eater") and used the vandalism as a "gotcha" moment. Merrilee viewed this as an opportunity to show how quickly the edits were reverted-the participant seemed to come away from this conversation with a new-found respect for the process.

On the other hand, Paul contradicted Merrilee's view of Wikipedia as robust as a reason why edit-a-thons are important. He described seeing the events as a space for hosts to teach participants about the fragility of the platform, particularly "how easy it is to disseminate fake news through platforms like Wikipedia," and "the importance of protecting it from being defiled."

Finally, within this theme, Therese stated she saw events as opportunities to secure advocates for Wikipedia, and not necessarily as a venue to create new content or encourage new active editors. She reasoned if people are only editors "once a year" when an edit-a-thon occurs "that's fine, because it also informs people about Wikipedia."

These motivations point to a shift in event objectives. Rather than adding new knowledge to the Wikipedia corpus, we see a desire to unpack Wikipedia for participants, and to help them understand (often with a critical eye) the processes behind Wikipedia as well as their implications.

4.1.3 Building connections beyond Wikipedia. Facilitators also saw edit-a-thon opportunities to partner with a diverse set of groups within and beyond their institutions. In university-attached events, this included working with student groups for more support and to improve event attendance. Kristan revealed:

Something that's really helpful is having partners. Having people with different levels of experience, or different connections within the community that they're in, so that you can do outreach in different areas. But also supporting each other through the process and learning together so all the weight is not on one person. Some of the most successful [edit-a-thons] here have incorporated student organizations.

Edit-a-thons at public libraries also partnered with groups to facilitate community-building experiences, such as acquainting participants with shared interests. Kim saw an opportunity to bring together people with shared passions as a part of her organizing and facilitating an edit-a-thon: 
The most successful thing for me has been appealing to a sense of, "This is your city, this is your passion, share that passion with other people." This is your chance to tell the story.

Leveraging relationships with community members to provide sponsorship is another reason to work with partners. The Kansas City Jazz edit-a-thon [17] organized by Kim was made possible because of a personal connection, which in turn led to publicity and future event funding. She continued:

I randomly happen to know a local distillery in Kansas City is owned by an avid jazz fan. And so I said, "Hey, I'm doing this event, do you by chance want to do anything with this event?" And he said, "Yes, absolutely." He made us a batch of signature cocktails for the event. I wrote that up in KC Studio magazine article, and then I had a guy cold-call me saying, "I read your article. I love what you're doing, how can I support you?" And then he sponsored the food for the next edit-a-thon. Our board chair-who has fallen in love with what we're doing-and his bank sponsored the next one. It's leveraging relationships.

Alex suggested a "prerequisite for successful development of new partnerships spaces [is] being able to pair offline events with a 'ready' online community" through the creation of "beachheads," or social infrastructures to better "defend" new contributions in the future. More specifically, he saw beachheads as being comprised of "a healthy group of activist-oriented individuals who [already] expect pushback to... be paired with an empathetic online cohort of people." Alex described areas in which this already occurs in communities surrounding edit-a-thon programs, such as Art + Feminism and Women in Red as well as the Human Rights and LGBTQ editing happening in Argentina, and can be used to further assist other marginalized people and topics.

These motivations point to a desire to build a larger social infrastructure larger than Wikipedia itself while also leveraging local contexts and connections. Student groups, activist collectives, and local businesses represent a diverse set of interests and stakeholders who can coalesce around a given edit-a-thon through a set of shared interests, values, and goals.

4.1.4 Fostering information literacy in local communities. Facilitators also saw edit-a-thons as opportunities to foster what they identified as information literacy within their local communities. This is related to the notion of building an understanding of Wikipedia (discussed earlier in §4.1.2), but goes beyond Wikipedia-specific knowledge. For example, Emily, Paul, and Therese specifically connected the skills learned in edit-a-thons to discerning reliability of digital data. Emily pointed out:

We're teaching the people who attend what a reliable source is, but there's a lot to unpack in that concept. Getting people to understand that is a great way to teach information literacy.

Paul defined information literacy as "figuring out what information is real from what's not," as well as "Determining what sources are dependable, relevant, noteworthy, or reputable." Similarly, Therese explained:

Information literacy is knowing how to find information, how to analyze the information to see if it's true or correct, and then how to utilize that new information that you found.

On a more basic level, Kim described the information literacy skills gained through edit-a-thons as including foundational digital skills, such as navigating the Internet: 
When I think about information literacy [gained] from Wikipedia edit-a-thons, it is teaching people everything, [starting] from how you navigate the Internet. That's something people don't necessarily know when they come in for an edit-a-thon, which is surprising to me-that people feel comfortable coming to something called a Wikipedia edit-a-thon without knowing [Internet navigation skills]. So some basic digital literacy is incorporated.

Both Kim and Therese used the same metaphor-edit-a-thons "sneak in" information literacy training just as parents sneak vegetables into food for kids to eat something they don't like. Kim divulged:

It becomes this really amazing and infectious tool you can use to do lots of other sneaky things. It's like sneaking vegetables into your kid's food. You can use Wikipedia to do a lot of other things if you're clever about how you do it.

Similarly, Therese admitted:

We can slowly get into their brains... it's like smushing up vegetables and putting it in so they don't know they're eating them. It's a great way for libraries to pass on information literacy.

Some aspects of information literacy can be considered as prerequisites for editing Wikipedia, and at first it may not seem surprising that the facilitators saw fostering information literacy as a part of what they do. What emerges from the data, however, is that the ability to edit Wikipedia is seen as a justification for developing information literacy, as well as a goal in its own right for some of the facilitators in our sample.

4.1.5 Investment in professional development. Finally, Merrilee viewed editing as an investment in her own professional development, and she described how she would set aside some time to do some editing herself during work-related events:

Honestly, I don't do as much editing as I'd like to. Intentionally setting aside some time for a little tiny bit of editing as the moment comes along feels like an investment in my own professional development.

\subsection{Facilitator strategies}

Facilitators employed a broad range of strategies to ensure successful edit-a-thons-these included managing expectations and enlisting help from established Wikipedia community members to work around and negotiate barriers to participation for the edit-a-thon participants.

4.2.1 Managing expectations. A central theme of strategies employed by facilitators was managing expectations among participants as to what can be achieved in a given edit-a-thon event. Facilitators noted newcomers would choose to attend edit-a-thons believing they would create an article from scratch, but that is not likely to occur within an event's timeframe. Merrilee pointed to a fundamental incompatibility between what she saw as a social nature of an edit-a-thon event versus the solitude, that in her view, "deep editing" required. In her experience:

A lot of times people, especially people who are new to Wikipedia, will come to an edit-a-thon thinking, "I have in mind this article I'm going to create from scratch. And I'm going to do it in this three-hour period." That is not going to happen. Even for the very experienced, pulling together an article from scratch in a short period is not going to happen. And edit-a-thons are social while deep editing tends to be solitary. But there are other, softer, less measurable things happening in edit-a-thons that are terribly important. 
Most facilitators mentioned the importance of starting small to encourage new users. This includes directing participants to find citations and/or update previously developed articles. Not only do facilitators find these activities easier to do, some pointed out this type of editing is seen as less likely to incur reversions. For example, Frank shared:

Edit-a-thons are a great way for new editors to come into the organization and begin to understand how the community operates [and] work with Wiki [markup] code. It also helps to create a structured environment for [participants] to understand where to start. And then we scale back expectations to adding a couple of sentences to a paragraph, rather than building a whole new article. Or adding a citation. Or adding categories to content that has not been categorized yet. The reputation a lot of people give Wikipedia, where anybody can edit anything, is both true and false. Anybody can edit anything, but anybody can also remove content.

To inspire new users, Tiffany stated she begins by encouraging people to read Wikipedia articles (if they haven't already) to see how an article might look before adding something to a pre-existing page to become comfortable with the process. She also mentioned providing participants with a suggested list of content to be updated (including local women artists) as part of her recent Art + Feminism edit-a-thons, but added she does not limit participants to list-related contributions. She explained:

I always encourage people to read through Wikipedia articles if they haven't already and get a feel for the tone and the language. And then add to a page that already exists, be it just a new sentence and citing it. Once you get more comfortable working on existing pages, that's when you can start an original. [...] We always create a sheet of women artists, many of them Dallas-based, to start. But if something [else] speaks to participants, go with it. But we do give little prompts, in case people are completely lost.

Similarly, Meg suggested meeting participants where they are by gauging comfort levels with finding resources, writing, and using technology. She finds university students who attend edita-thons are already comfortable with "entry-level" editing, such as adding a sentence or source here-and-there (which she sees as still valuable), while others dive right in, such as a student who developed a stub (i.e., an under-developed) article on a female composer into a much greater depth, including embedding multimedia.

Other facilitators found alternative pathways to entry to be more accessible. For example, Merrilee noted "easy wins" (i.e., initial activities that are more accessible to newcomers than creating an entirely new article) which include creating an info box, adding a photograph (especially if it already exists in Wikimedia commons), adding categories to articles, and interlinking/connecting orphaned articles. Merrilee found these smaller tasks are important, as new participants "find something where they feel like they can make a real genuine contribution."

An interplay thus emerges between participant agency, event structure, and facilitators' efforts to strike a balance between the two. Facilitators recognize that participants new to editing may be more successful with smaller changes that are actively scaffolded. At the same time, they are aware of the importance of allowing participants to follow their own interests and in the process, if needed, carve out their own pathways to participation.

4.2.2 Framing edit-a-thons as social events that emphasize personal interactions. Another strategy adopted by facilitators is emphasizing the social nature of edit-a-thon events. This builds upon and leverages shared interests and the importance of community building (as described earlier in $\S$ 4.1.3). 
For example, Tiffany described:

Our participants talked to each other. They even asked each other for assistance or,

"What do you think about this?" There's a lot of learning and teaching going on.

Similarly, Leslie noted her most successful edit-a-thons had collegial atmospheres; event spaces were welcoming, with people talking and laughing together, and even physically "leaning into each other and showing each other their laptops or asking each other questions." This is further reinforced by Tiffany's experience, in which making participants feel comfortable and, in particular, approaching the event with humor "is always a way to help people become relaxed." Tiffany added fostering a fun environment helped events become more successful than hosting "a cold situation where nobody talks to each other."

Edit-a-thons bring potential and active Wikipedia editors together in a shared, physical space. An affordance of such a context is the ability to foster face-to-face social interactions-something facilitators whom we interviewed understood and incorporated into their facilitation strategy. Leslie recalled:

I remember there was a lot of talking and laughing with each other. I remember people sitting side-by-side on couches and chairs, all over the space, and leaning into each other and showing each other their laptops, or asking each other questions. It was a really nice atmosphere with a nice buzz of collaborative working and having fun.

4.2.3 Choosing an appropriate venue. Facilitators also paid careful attention toward choosing an appropriate physical venue for hosting an edit-a-thon and ensuring the venue and the institution associated with it were well aligned with what the event sought to achieve (e.g., bringing people with shared interests together). We saw earlier in $\S 4.1 .3$ how Kim's edit-a-thon took place in an otherwise inaccessible space, as the Kansas City Jazz Museum would not be open to the public on a Monday or after 6 o'clock in the evening without the event. Kim shared:

Being able to host something at the Jazz Museum was a partnership. [The museum] was closed to the public, but they opened specifically for this event... We turned it into an experience and a community building tool. We've had people at every single event who would never otherwise have met, and they're coming together around a common love, whether it's philanthropy, Black history, or something else. It's a cool way for people to meet each other.

Similarly, Merrilee saw the events as an opportunity for the public to feel more comfortable visiting a cultural institution-even if it is already open:

I attended an edit-a-thon at the San Francisco Museum of Art's library. People were like, "Oh, I want to go see the library at the San Francisco Museum of Art," even though it's open all the time. You can walk in anytime you want. I think people like the opportunity to see a space they don't normally see. Sometimes at conferences where I've organized an edit-a-thon, I've done it at a time where they're doing workshops, so people are a captive audience. If you're not going to a workshop, here is a free activity you can attend in parallel. And a nice location always draws people.

A concrete illustration of how partnering with a local public library helped boost attendance is Meg's Black History Month-related edit-a-thon:

We hosted the Black History Month edit-a-thon at the Monroe County Public Library [instead of campus]. The previous year, almost everyone who came were librarians, with about three students. We needed to broaden our work out for the wider community. And because our multicultural outreach librarian worked extensively with people who are beyond the campus community and has so many contacts, we hosted the 2019 
event at the public library. We had between 20 and 25 people showing up. Less than half were librarians. We even had a local reporter show up to interview people too.

The venues chosen by the facilitators expose a range of underlying intent. Some represent a desire to be in-line with the chosen theme or interest of the edit-a-thon, others are an attempt to engage a larger number of participants, while still others represent a motivation to encourage visiting a cultural institution that may not be accessible otherwise.

4.2.4 Choosing appropriate evaluation criteria. Another theme that emerged out of our interviews was the careful attention of facilitators toward understanding how successful their events were. Wikipedia provides a dashboard tool that allows one to see the outcomes of a specific edit-a-thonhowever, our interviews revealed that dashboard-centric quantitative metrics may not be the best means by which to judge the success of an edit-a-thon event. In some cases, quantitative metrics captured by the dashboard may not even be a genuine reflection of the event. For example, the 2017 Art + Feminism Dallas's event dashboard shows 6 editors, 15 total edits, and 2 articles edited [10] But Tiffany, as mentioned in media coverage for the event, recalled, "We had about 20 attendees who ranged in age from their early 20 s to their late 50s [49]. Tiffany also suggested more qualitative metrics with which to define an event's success:

I judge the success of something with how it changes the person. And that's not hard data, not facts. To me, that's what's important-putting a program together that means something to people.

While Tiffany's library did provide printed program surveys for participants to fill out after the event, she stated that she does not find surveys to be the best method of gathering information either:

I do my best to create a welcoming and safe environment for everybody. We have printed program surveys, but to me, that's a cold way to go about gathering information. I don't want to just hand someone a form. I'd rather talk and engage with them. That's helped with return rates as well. People not only come back to these events, but to come back to the library in general.

Measuring success for an event such as an edit-a-thon is an important but difficult task. The broader Wikipedia community provides some tools and strategies-however, our findings suggest that facilitators not only recognize these approaches show only a part of what an edit-a-thon might accomplish, but also, they come up with their own metrics and criteria to understand how successful the edit-a-thon they hosted was.

4.2.5 Workarounds via partnerships with established Wikipedians. Partnerships with established members of the Wikipedia community provided a means to circumvent technical and non-technical restrictions. For example, Paul described how partnerships with Wikipedians-in-Residence ${ }^{2}$ allow facilitators to circumvent frustrating restrictions, such as limitations placed on the number of new accounts created from one IP address.

Therese recalled knowing insider advocates who helped keep open multimedia content online, such as photographs by a university photographer:

All pictures of these chemistry professors were taken by the chemistry photographer, who put them on the University's website. So we were using those, and Wikipedia is like, "No, you can't use them." And so I asked the photographer, "Can you put them into WikiCommons for us?" He did. But that wasn't enough. And so he had to write

\footnotetext{
${ }^{2}$ Wikipedians-in-Residence are members of the community who are hosted by institutions (such as libraries and museums) and establish a relationship between the institution and the Wikipedia community.
} 
and say, "No, these are open access. These are mine. I'm giving permission." And again, we got one of the local super editors to help us clear the way. So all the pictures got put into the [Wiki]Commons.

Personal connections with Wikipedia admins were also helpful to "win" editing wars and reversion issues. Alice advised facilitators work "with folks in the local Wikipedia users group who are more experienced editors and have that weight of authority within that community" as they are "invaluable resources in terms of crafting an article so it will stick." In some cases, the established member of the Wikipedia community was the facilitator themself. For example, Merrilee suggested that the sheer amount of time and number of edits she produced makes it easier for established editors to believe her updates:

If somebody looks at my user page and my contribution history, they're going to see I've been editing Wikipedia for a long time. If I make an edit, it's much more likely to stick than if you created a user page yesterday and you've made an edit. You're going to come under scrutiny for no good reason, other than you've just created a user account. There's a lot of privilege that comes with longevity.

The large and complex nature of Wikipedia's norms can make it hard for less established community members to contribute otherwise acceptable (within Wikipedia's own rules) content, or in some cases, get started contributing. These examples show how facilitators adopted creative strategies toward making sure content produced during their events could keep from being deleted, or in some cases, participants of their events could get started within the community. That said, our interviews also revealed a number of other challenges the facilitators struggled with. We describe these challenges next.

\subsection{Facilitator challenges}

Despite the use of a broad range of strategies used to run edit-a-thons, facilitators faced a number of deep-rooted challenges that represent systemic issues with Wikipedia (documented in existing work such as $[2,21,22,56,57])$, and, in some cases, online peer production communities in general [36].

4.3.1 Systemic biases. Facilitators discussed how Wikipedia gaps are indicative of larger systemic biases that have remain unaddressed with the community. Merrilee continued her description of bias against new editors and its implications:

You wind up with a set of editors who have taken on administrative responsibilities and who become increasingly hardened. And then new people are being cut far less of a break than they used to be, which is why an appreciation and understanding of how Wikipedia works is worth [spending] time on. Even if you don't edit, you may be able to help somebody who is editing overcome their challenges. I've never gone through a really severe edit war, but I could coach [others on how] to avoid that. It's not because I've made thousands of edits. It's because I've been reflective of how the system works, and its flaws, and can think creatively about workarounds for those.

Leslie saw similarities between gaps in archives and in Wikipedia as a means to reconsider "What's in it? Or how does it get there? How does it work? Whose stories are very well told?" Moreover, she shared her frustration with Wikipedia for its inability to figure out better methods of resisting issues that have already been raised (and solved) related to marginalized voices in archives, noting that Wikipedia does not have to be the same as a history book. She asserted:

I don't want Wikipedia to become something that perpetuates things we know have been done wrong in the past. Not just on Wikipedia, but in general-ignoring certain people's stories, or how those decisions are made. We should learn from our past 
mistakes. And we know how to do better. Why do we have to [make Wikipedia] exactly the same as a history book? There must be something different. We should be a bit more flexible.

Beyond flexibility, Sarah offered another possibility to address gaps by removing the notability standard ${ }^{3}$ altogether, arguing "Notability makes more sense in a print document that's limited by size." Sarah recalled the difficulty of justifying articles about a historically women's college's dormitories, even though other schools had similar established content:

While I agree that maybe we shouldn't go into detail about every residence hall in every college, but if Harvard, Yale, and UMass-Amherst had it, I was going to create it for our halls, too. So I got frustrated raising awareness of misogyny and marginalization of women... It felt like I was doing work for an organization that didn't care about rectifying that fact.

While further discussing systemic biases, Sarah suggested removing notability standards could be viewed as a form of reparation. This suggestion echoed concerns from other facilitators, such as Emily who had hosted an edit-a-thon focused on African American female artists. She shared:

After every edit-a-thon I participate in, I go back and see which articles stuck. That edit-a-thon [focused on African American female artists] was the one where almost all of the newly created articles had been taken down on the basis of notability.

Another facilitator, Frank, recalled devising an alternative source for notability-linking to Library of Congress recordings versus a "spammy" looking music label website:

Someone was working on editing the Wikipedia page for her husband, who was a folk music artist and member of the Lumbee tribe. It was a Native American edit-a-thon for the Lumbee people of North Carolina. He had contracts with recording studios and is a noteworthy person. However, the recording studios were very bad at building websites, [which] looked very spammy and were being rejected as citable sources. As we dug into it further, I pointed out that anytime a new album is released and goes through a regular recording studio, a copy is added to the Library of Congress. We were able to cite the Library of Congress as a good reference source.

Similarly, Meg shared that Wikipedia's bias "towards secondary published sources is something that often works at odds for historic or recent figures, many of whom happened to be women and people of color who don't have a plethora of secondary published sources printed about them." She also added that being up-front about the Wikipedia community's biases (against primary sources, which disproportionately impacts women of color) as part of the introductory presentation at an edit-a-thon may help the participants become more aware of this issue and lessen the chance of their edits being reverted due to an increased reliance on primary sources. Meg remembered:

[Another event facilitator] pointed out Wikipedia is biased against primary sources, which was helpful not only for me to know, but for all of the participants because we were developing Wikipedia articles for which only primary sources existed. [We were trying] to celebrate and emphasize women of color who had some connection to my institution.

Facilitators also stated alternative sources of data, such as oral histories, were rejected by the larger Wikipedia community to its detriment. Emily noted:

Statistically, people who contribute to Wikipedia tend to be male, white, cis, hetero, and educated. That is changing. I think it's going to take a long time before it changes

\footnotetext{
${ }^{3}$ The notability standard is used in Wikipedia to determine if a particular topic warrants its own article page or not. Taraborelli and Ciampaglia provide an analysis of how notability is decided [52].
} 
significantly. But the deeper, more entrenched problem is historically, we have a system of knowledge, based on hundreds of years of publishing, that benefited from and supported white supremacy. Oral traditions of knowledge are not valued. They're not considered citable source and therefore rejected as unreliable sources.

Most of the librarian facilitators interviewed responded that they are aware of tension between Neutral Point of View (NPOV) ${ }^{4}$ as a goal/pillar of Wikipedia and the contemporary philosophies eschewing objectivist ontologies/epistemologies. Yet the solution offered for controversial subjects-citing some groups state one opinion while other groups state another-seems insufficient, particularly as content is embedded within larger systems of bias in Wikipedia (e.g., oral histories not considered notable sources). Situating arguments in this manner may also seem fair or balanced on the surface, but can easily reproduce harmful arguments (e.g., stating, "some people believe the Lumbee are not a 'real' tribe while others disagree"). Therese noted facilitators have helped bring some of these issues to the forefront within the Wikipedia community:

Edit-a-thons are influential because they are run by professionals-librarians or teachers. We're forcing Wikipedia to realize its limitations... It's skewed against women and other people outside of the white male, Northern Hemisphere [norm]. If I was a lone woman editing by myself, I wouldn't have the voice facilitators have. We've been attending the meetings, like Wikimedia conferences and summits. We're on the side of diversity, inclusion, and equity. I think we're a louder voice in the fray.

Issues with NPOV also provides the only example recorded of removing content from a Wikipedia page during an edit-a-thon. Therese described how she noticed women in science were having regular "info boxes" instead of "scientist info boxes," which contained more relevant information (including thesis advisor, colleges attended, important awards). She also encouraged participants to remove "fluff" about female scientists, such as information on who they are married to, their children, and other nonrelevant content:

It used to be women scientists got boxes that were just info boxes, they weren't the "scientist" info boxes. We started changing that, so you knew who their thesis advisor was, what college or university they went to, and important awards they received. And we started taking out the fluff in women's articles, which would usually say, "She's married to so-and-so and has three children." But if you read [about other male] scientists, [content] is not about their families.

These issues collectively raise questions of not only who gets represented on Wikipedia, but also how they are represented. Facilitators notice these biases, grapple with them, and in some cases, even find successful workarounds for them (such as Frank's and Meg's solutions). However, these gaps also belie deeper questions regarding the purpose and fruitfulness of edit-a-thons, as described next.

\footnotetext{
${ }^{4}$ Wikipedia defines NPOV as "representing fairly, proportionately, and, as far as possible, without editorial bias, all of the significant views that have been published by reliable sources on a topic" [61]. NPOV is deemed so essential to the site that it became a fundamental principle for the entire Wikimedia Foundation-a "mandatory core approach to neutral, unbiased article-writing"[60]. Investigating NPOV uncovers complex issues of power, control, biases, and marginalization. Writing about (and from) the early history of Wikipedia, Reagle, defended the use of the term neutral as "far superior to the notion of 'unbiased'... since that connotes a sense of epistemic purity whereas neutrality is indicative of a careful and fair balancing." [45] Yet Matei and Dobrescu reasoned the NPOV policy is unenforceable and often used as justification for bias, as "truth and 'neutrality' become whatever users with power (typically administrators) intend it to mean and this is enforced not by intellectual consensus but by topic 'squatting'”[34, p. 49]. Similarly, Mai noted that instead of accommodating conflicting ideas, NPOV "advances the notion that topics are value neutral and true at the center and that a plural minority viewpoint exist[s] only at the edges, outside comprehension within the majority viewpoint" [33, p. 21].
} 
4.3.2 Uncompensated emotional labor from marginalized groups. A discussion of bias, and the subsequent discussion on how to address bias at the level of the Wikipedia community, often led to questioning what individual facilitators and edit-a-thon participants should or should not do. For example, Merrilee stated the well-documented coverage of Wikipedia's gender bias led a fellow facilitator to ask her "is it okay to have an edit-a-thon that's not about women?"

Taking a stronger stance, one facilitator we interviewed stopped organizing edit-a-thons altogether, as they perceived the events to be a means of soliciting underrepresented groups to produce content and perform emotional labor for free. Sarah disclosed:

There is an increase in awareness of competencies around emotional labor, how we spend our time, and who gets asked to do the work. I think Wikipedia systems have not caught up with these shifts. I know it's not where I want to put my effort, because being a faceless editor makes me less interested.

\section{$[\ldots]$}

For people in the Wiki GLAM ${ }^{5}$ community, it's valuable for them to teach people how to edit. And [edit-a-thons] teach students about what's under the hood in a Wikipedia page. But it's grunt work. It's heavily female communities doing a lot of grunt work for an organization that has long standing issues with diminishing the contributions of people who aren't cis men.

Sarah was correct in pointing out the gender gap in Wikipedia, which is well-documented $[20,24,30]$. Moreover, gaps and biases go beyond gender. Emily shared a story of inviting a member of the Lumbee Tribe to participate in an edit-a-thon. Her invitation was turned down-the reason given was the current state and history of Wikipedia's article on the Lumbee:

We hosted a North Carolina American Indians themed Wikipedia edit-a-thon, and that experience really opened my eyes. I knew Lumbee Indians had a difficult struggle to achieve any kind of government recognition as a tribe. When I told my friend [a member of the Lumbee Tribe] we were doing this edit-a-thon and invited him to participate, his response was, "I don't want to have anything to do with Wikipedia." Because the article about Lumbee Indians, at that point, was locked because people had gotten into editing wars. People had come in to contest the Lumbee identity-as it is understood by members of the tribe-based on their own agenda.

As with Wikipedia contributors in general [35], edit-a-thon participants donate their labor when they add content to Wikipedia. If people see Wikipedia as a place where their identity is being questioned, or if the labor they donate is rejected through the reversion of their edits, it is not unreasonable to assume that they will be less likely to participate. Facilitators recognized this challenge and the potentially exploitative nature of edit-a-thons. On the other hand, some facilitators such as Merrilee's co-facilitator, who wondered if it was okay to host an edit-a-thon that was not about women, saw edit-a-thons as a way to actively counter this culture of exclusion by suggesting edit-a-thons should be more focused toward addressing gaps in Wikipedia.

4.3.3 Retention. Finally, an issue faced by facilitators which emerged from multiple interviews centered on retaining participants as editors in the community. Alex noted edit-a-thons may not be the best method for new editor retention, as the events require large amounts of energy and retain approximately one in twenty participants. He articulated this unmet expectation, especially among

\footnotetext{
${ }^{5}$ The GLAM-Wiki initiative ("galleries, libraries, archives, and museums" with Wikipedia) helps cultural institutions share their resources on Wikipedia through collaborative projects with experienced editors.
} 
new organizers "that edit-a-thons are about creating content and retaining people." Furthermore, Alex suggested event facilitation should be viewed as "only the gateway to organizing."

While many edit-a-thons do not have a specific intended group of potential participants, Alex cited the targeted models used in the Czech Republic and Armenia as more successful for creating a habit of contribution. In the Czech Republic, events are specifically aimed towards seniors, with biweekly editing classes taking place at public libraries over the course of two months. In Armenia, successful editor retention is seen in their WikiCamp summer program, where young adults (aged 14-20) edit Wikipedia along with participating in sports, music, and other activities [13] .

Meg attributed the lack of editor retention to what she saw as the opacity of top-level editorial decisions. In particular, she believed new users did not know how decisions were made regarding which content is kept, as there is a "complete lack of transparency about who is making these decisions at the upper levels." Furthermore, Meg noted it might be intimidating for new users to be asked to edit something they see as a valuable source, and frustrating when their edits are not valued.

Tiffany suggested creating a supportive space for retention, as participants have returned to her to share how proud they are of their work-especially if participants had difficulties or struggled during the event itself:

It comes from building a comfortable experience from the get-go. Especially if [participants] have struggled at the event. They're really proud to [return and share], "Look how I did this. I fixed it. This is great." It goes back to the people and making a supportive space.

Retention is a serious challenge within the broader Wikipedia community [23], though edit-athons attenuate the rate of attrition to some extent [15]. Our findings suggest not only do facilitators recognize this and attempt to understand what leads to this, but also, they formulate strategies to actively counter the high attrition rate and ensure newcomers continue to participate in the community beyond the edit-a-thon they attended.

\section{DISCUSSION}

In this section, we use the theories of information ecologies and public pedagogy to situate our findings. We employ these theories in an interpretative way, where we seek an "understanding of the studied phenomenon," acknowledging that this assumes "emergent, multiple realities; indeterminacy; facts and values as linked, truth as provisional; and social life as processual" [8, p. 126]. Building on this theoretical grounding, we then consider the implications of our findings-drawing connections to not just the area of Wikipedia research, but also broader CSCW and HCI scholarship.

\subsection{Edit-a-thons as information ecologies}

Historically, edit-a-thons began as a means to leverage knowledge from established repositories, but shifted to focus on editing tutorials targeting new contributors between 2011 and 2018 [51, p. 123]. The past few years have also seen significant interest in edit-a-thons explicitly intended to close gaps and address biases within Wikipedia. One notable example of this is the Art+Feminism edit-a-thon series, which has been held throughout the world yearly. Themes regarding these purposes of edit-a-thons emerge from our findings as well. However, the facilitators we interviewed also emphasize other important reasons for edit-a-thons' continued significance. Some of these are specifically about Wikipedia (e.g., enabling participants to understand how Wikipedia works in general), but others are broader (e.g., fostering information literacies in local communities and building local shared-interest groups). This suggests edit-a-thons are not simply about editing. Furthermore, even as editing remains one goal among many, the relationship between participants 
and editing varies considerably in ways driven by local considerations (e.g., institutional, facilitator, and participant values). A possible theoretical frame to understand edit-a-thons in the form that emerges from our interviews is the notion of information ecologies [37]. Information ecologies, as described by Nardi and O'Day, are

[... ] a system of people, practices, values, and technologies in a particular local environment. In information ecologies, the spotlight is not on technology, but on human activities that are served by technology. [37, p. 49]

The "system" facilitators construct around edit-a-thons represents such ecologies, as they shift the "spotlight" from editing Wikipedia onto activities and, more importantly, relationships which extend beyond Wikipedia to a range of "people, practices, values, and technologies." For example, when edit-a-thons are framed as social events that emphasize personal interactions (§ 4.2.2), we see the event's focus shift from editing to bringing people with shared interests together.

Nardi and O'Day suggest several key properties that "characterize" information ecologies (p. 50). Our findings echo such properties as well. We see a complex system of interrelated parts and relationships emerge around edit-a-thons-an example being the relationships that emerge between edit-a-thon participants, facilitators, and cultural institutions (§ 4.1.3). We see diversity being acknowledged when facilitators explicitly describe the importance of meeting participants where they are (§ 4.2.1). As new strategies emerge to ensure contributed content does not get erased or reverted (e.g., Frank's strategy to cite Library of Congress records in $\S 4.3 .1$ ), we see instances of evolution. In an edit-a-thon information ecology, facilitators form the keystone species-"whose presence is crucial to the survival of the ecology itself" (p. 53)-by serving as "translators, facilitators, and teacher" (p. 53). Finally, the design of edit-a-thons are often shaped by considerations and factors that are uniquely local (e.g., the partnerships described in § 4.2.3) suggesting locality.

Moreover, in describing how one might go about evolving information ecologies, Nardi and O'Day suggest it is important to "work from core values"-which is echoed by facilitators as they discuss their motivations for hosting edit-a-thons (§ 4.1.1).

The connections described above suggest information ecologies provide a useful theoretical frame for understanding edit-a-thons. However, it is also important to consider that within the information ecology of an edit-a-thon, the activities of teaching play a central role in helping the ecology emerge and evolve. Our findings show the facilitators we interviewed carefully and thoughtfully engage in practicing a certain pedagogy, and the information ecologies of edit-a-thons that develop are the results of their pedagogical actions. Furthermore, we see the notion of resistance appear in the action of the facilitators as they counter systemic biases and gaps in Wikipedia's knowledge-base and in the larger Wikipedia community's norms and rules of participation. Yet Nardi and O'Day's list of characteristics leaves little room for resistance. In fact, their framing explicitly downplays the role of resistance in making an information ecology happen, suggesting a focus on "engagement and participation" [37, p. 57] instead. Our data shows the opposite: resistance and negotiation is a prerequisite to productive participation and engagement in the context of edit-a-thons, especially events which explicitly attempt to address biases in Wikipedia. This is not a new critique for information ecologies-Bowker, in his review of Nardi and O'Day's work described in length what he saw as an "inattention to the dynamics of power" [4, p. 145]. Thus, while the notion of information ecologies help us understand what edit-a-thons are, this understanding is partial. Our findings also provide a complementary account of how edit-a-thons come into being through pedagogical practices steeped in resistance. For a theoretical understanding of this specific type of pedagogy practice, we turn toward another body of theory, public pedagogy. 


\subsection{Edit-a-thons as sites of public pedagogy}

The theory we draw from to understand how edit-a-thons emerge and evolve is that of public pedagogy $[19,48]$. In a comprehensive review of literature on public pedagogy, Sandlin et al. [47] trace the evolution of the term in academic literature between 1894-2010. Originally a theoretical construct for understanding education beyond formal schools, the term public pedagogy is increasingly used by feminist and critical theorists to engage with educational processes in a wide variety of contexts. Sandlin et al. note that while early uses of the term denoted "education in the service of the public good" (p. 342), later scholars view public pedagogy as "a means of responding to oppressive aspects of cultural life" where "participants become their own curriculum coordinators." (p. 342). The facilitators whom we interviewed carried out public pedagogy practices as they designed and implemented experiences to support their edit-a-thons participants. They did so with an eye toward a form of "public good," which responds to and attempts to counter "oppressive aspects of cultural life" (e.g., biases within Wikipedia's public knowledge system). Moreover, for some edit-a-thons, participants become their own curriculum coordinators (e.g., as described in $\S 4.2 .1$, choosing activities and topics based on their own interests and comfort levels).

Henry Giroux, a prominent figure within public pedagogy scholarship, framed public pedagogy as "cultural politics" [18] by connecting public pedagogy to Stuart Hall's work on cultural studies. Giroux suggests:

Hall's work provides an important theoretical framework for making pedagogy central to the theory and practice of cultural politics. His work is also crucial for understanding pedagogy as a mode of cultural criticism that is essential for questioning the conditions under which knowledge is produced and subject positions are put into place, negotiated, taken up, or refused. [18, p. 342]

Wikipedia is not only one of the most-visited websites in the world [1], but knowledge within Wikipedia is often re-used by other popular websites including Google and Facebook [7]. Google search results page for a range of topics (e.g., prominent people, historical events, information on countries) highlight snippets from the Wikipedia article about a particular query inside a "knowledge panel," which is displayed alongside search results. In an effort to combat "fake news," Facebook began including Wikipedia content inside news feed links in April 2018, stating, "we're making it easy for people to view context about an article, including the publisher's Wikipedia entry," in their press release [27]. As a result, the biases and gaps in Wikipedia not only present an incomplete body of knowledge for Wikipedia users, but also impact the billions of search and social media users who may not visit Wikipedia directly. These users' understanding of topics (or lack thereof) could potentially be driven by biases within Wikipedia. Our findings reveal how facilitators of edit-a-thons not only understand and question these biases, but also actively attempt to address them. These acts of resistance represent struggles around how knowledge is produced. Drawing from Hall, Giroux describes "public pedagogy as a struggle over identification" (p. 352), which is clearly applicable to the actions of facilitators. The challenges they confront while pondering whether it is okay to have edit-a-thons not focused on women (§ 4.3.2), or when arguing that alternate sources of data are rejected by Wikipedia to its detriment (§ 4.3.1), fundamentally represent, as Giroux puts it, struggles over representation and identity.

For Giroux, through Hall's lens, public pedagogy represents "a moral and political practice rather than merely a technical procedure" [18, p. 354]. We see a similar de-centralization of technical procedure for edit-a-thons in our findings as well. Furthermore, Giroux suggest the need for a public pedagogy project "to begin at those intersections where people actually live their lives and where meaning is produced, assumed, and contested in the unequal relations of power that construct the mundane acts of everyday relations" [18, p. 355]. As facilitators work from within 
their local relationships, interests, and knowledge (§§ 4.1.3, 4.2.2, 4.3.1), we see a similar practice emerge, where knowledge and meaning derived from lived lives is produced and contested within the power and relationship structures of the larger Wikipedia community.

\subsection{Implications}

Framing edit-a-thons as instances of information ecologies provides an alternative approach to evaluating the events. Our findings show facilitators engage in capturing formative signs of success in ways guided by local values and aspirations, moving beyond quantitative dashboard tools provided by Wikipedia (§ 4.2.4). What might a broadly applicable strategy that seeks to understand and evaluate individual edit-a-thons look like? Drawing from Peavy [43], Nardi and O'Day introduce the notion of "strategic questioning" (p. 71) as a way of making local knowledge, values, and aspirations that form the basis of a given information ecology surface through a dialectical process Strategic questioning involves descriptive questions (e.g., "observational questions" to bring out what can be seen and/or heard) as well as questions that "dig deeper" (e.g., "visioning questions" to identify the ideals and values of the people in the ecology). As Tiffany argued in $\S 4.2 .4$, evaluation is fundamentally about how something "changes the person," we see an example of a strategic question already being formulated. Nardi and O'Day remind us that "local knowledge is required both to formulate and respond to questions" (p. 74), and this is true for edit-a-thons as well-a broad set of strategic questions designed for understanding and evaluating edit-a-thons will ultimately need to be supplemented by local organizers and participants who know their community and their ecology best. Furthermore, Nardi and O'Day posit strategic questioning as a tool for anyone who wants to become involved in information ecologies-we echo them to suggest that facilitators, participants, researchers, and supporting institutions can use strategic questioning to design, interrogate, and evaluate edit-a-thon-events.

The notion of strategic questioning also becomes a valuable tool within the complementary framing of edit-a-thons as instances of public pedagogy. Practitioners and scholars of public pedagogy can use strategic questioning to understand and evaluate the context they are studying This new connection bridging information ecologies with public pedagogy provides a second implication from our findings.

Another important implication for work on edit-a-thons centers on existing gaps in public pedagogy scholarship, which can serve as guidance for future related research. Sandlin et al., in their review of public pedagogy scholarship [47], suggest a number of understudied areas. Most relevant to our work and context, they call for a deeper understanding of "how these educational sites and practices actually work to teach the public and how the intended educational meanings of public pedagogies are internalized, reconfigured, and mobilized by public citizens," (p. 359), or in other words, how public pedagogy operates. Our work focuses on the motivation, strategies, and challenges faced by facilitators. Relatedly, Sandlin et al. also point to the need of understanding "what public pedagogies mean and do from the viewpoint of their intended audiences" (p. 361). In the case of our work, we do not consider the perspective of edit-a-thon participants (i.e., "audiences") at all. While some existing work on edit-a-thons study the processes (e.g., through analysis of online activity, as well as qualitative interviews [29]) and outcomes for participants (e.g., through analysis of online activities of participants during and after an edit-a-thon [15]), qualitative, observational work during the edit-a-thon seems to be an understudied area. Additionally, our findings, particularly sections 4.1.4 and 4.2.4, suggest intended outcomes as imagined by facilitators (e.g., fostering information literacies) extending what has been studied by scholars of edit-a-thons so far. Relatedly, we found "the public" for edit-a-thon events may include not only facilitators and participants, but also the local community, thus calling for wider analyses in terms of impacts on local communities and institutions (§ 4.1.3). 
Finally, though we frame our implications as about being edit-a-thons, our implications may apply to other contexts, such as structurally similar offline events that connect to online peer-production communities (with caveats on generalizability, discussed in §6) as well. Many of these events have enough characteristic features in common with edit-a-thons so as to enable the application of the theoretical framing we have employed and the implications that we outline. For example, Ntabathia [41] found the categorization system in OpenStreetMaps (OSM)-a peer produced geographic information system-created barriers for members of certain communities to participate in the peer-production process. Through the use of a custom tool and by engaging with mapping party events in different locations in Kenya, Ntabathia found, for example, that locations of street vendors commonly found in informal economies could not be added easily to OSM maps as there was no appropriate category for them. Similarly, since an OSM category for a dispensary (an outpatient and often government-run health facility that is smaller than a clinic) did not exist, a mapper labelled it as a clinic instead (p. 180). Such locally-visible structural barriers, as well as the processes of negotiation and strategizing to ensure local knowledge and lived experiences is recorded, echo the experiences we report in this study. Furthermore, as with Wikipedia data, OSM data shows up in contexts beyond the OSM website itself $^{6}$, and data on OSM is used in crisis response systems [42] after natural disasters. Consequently, in a similar way as discussed with Wikipedia data earlier in this section, what is recorded in OSM and what is not has implications beyond the immediate users of the OSM website.

Given these similarities, it is possible that both the notions of information ecologies and public pedagogy can be used to interpret and analyze the structure of OSM mapping parties, and the technique of strategic questioning may be used as a pathway for the design of, participation in, and evaluation of such events. Clearly, local knowledge, values, and aspirations drive both genres of events. As with Wikipedia edit-a-thons, success (as defined by facilitators, funders, participants and/or researchers) for OSM mapping parties may not simply depend on the total number of new points added to a map or total number of new editors recruited. While these are important metrics, they capture only part of the story. Drawing from our use of information ecologies as an analytical frame, it is equally important to consider the impacts of such work on the local community, including the benefits of involving local cultural institutions, supporting professional development, fostering of information literacy among participants, and building local relationships. Similarly, drawing from our use of public pedagogy, we urge future researchers to recognize these events as venues where the evolution, negotiation, and contestation of what belongs in peerproduced knowledge-bases take place. Furthermore, building on existing scholarship on public pedagogy, especially the gaps identified by Sandlin et al. that we discussed earlier, we suggest that scholars studying peer-produced geographical information systems may find new insights in what the pedagogy of public mapping might look like by engaging with participants of OSM mapping parties.

\section{REFLECTIONS, LIMITATIONS, AND FUTURE DIRECTIONS}

As co-authors of this work, we feel it is important to state we share many of the personal values held by the facilitators whom we interviewed. Furthermore, the mission of our own institution (a large public research university in the United States) also echoes many of the institutional values articulated by facilitators in our interviews. This institutional affiliation, apart from having implications for our values-system, also allows us to speak from a position of privilege.

\footnotetext{
${ }^{6}$ https://welcome.openstreetmap.org/about-osm-community/consumers/
} 
Moreover, as researchers we acknowledge that the "subjects" of our research deeply care about the topic of our research [26], and we recognize our "research not only represents or intervenes but also creates new circuits" [26, p. 12] and relationships within the culture we seek to study.

Our research design and approach does not necessarily lead to generalizability. That said, we hope that our work is taken as a starting point by other researchers to investigate the phenomenon of edit-a-thons in more varied contexts. For example, all the participants for our study are from the United States even as edit-a-thons take place throughout the world in languages other than English While many edit-a-thons are intended to close gaps in Wikipedia content, it may be entirely possible that the motivations, strategies, and values of facilitators will differ. Differences may depend on individual beliefs as well as the topic and context of each edit-a-thon, including the type of content being added (e.g., adding photos may have different dynamics than adding text). Though we offer a set of theoretical framing for interpreting edit-a-thons, we recognize this may not be adequate to understand all instances of edit-a-thons and we look forward to other scholarly contributions, which will allow us to understand edit-a-thons in all their variations and unique qualities.

Finally, we reiterate our earlier acknowledgement (§ 5.3) that we lack engagement with edit-athon participants in this study. There is an emergent body of work that considers the perspectives of edit-a-thon participants (e.g., $[15,29]$ ), and we offer our work as a complementary analysis that focuses on the other group of stakeholders (viz., facilitators) who are involved directly in edit-athons. That said, studies of participants, including attempts to understand their motivations and aspirations, represent a potentially rich area of work for scholars interested in studying edit-a-thons and similar events.

\section{CONCLUSION}

In September 2019, as we were conducting this study, the Wikimedia Foundation released a highlevel report titled "Wikimedia Movement Organizers: Understanding the People who Power the Movement" [58]. "Organizers" in this report include not only people who organize and facilitate edit-a-thons, but also those who disseminate Wikipedia content in settings with limited Internet connectivity, coordinate large-scale contribution of media artifacts (e.g., historical photos) and others from cultural and educational institutions. Many of the findings of the report, especially on organizers' motivations and the results of their efforts, echo what we find in our study. We also see a de-centering of editing-"editing is not a requirement," (p. 26)-and a recognition that the work of these organizers enable the integration of Wikimedia "into a wider knowledge ecosystem" (p. 3).

Our work complements this report by offering an in-depth and independent analysis of edit-athon facilitation. We focus on edit-a-thon facilitators' contributions to the creation and evolution of local knowledge and information ecosystems-and how these ecosystems connect to and interact with the broader Wikipedia community and ecosystems. This process has broad implications as it represents how knowledge-particularly of subjects at the margins and underrepresented in Wikipedia-is produced, negotiated, and recorded within an online community. The resulting knowledge, as discussed earlier in our introduction and discussion sections (§ $1, \S 5.3)$, is not only visible within Wikipedia, but also present in Google search results, Facebook feeds, and other seemingly independent contexts that constitute our broader digital cultures. Emergent artificial intelligence technologies also use Wikipedia content as training data, which can further propagate Wikipedia's gaps and biases [32].

Along with an analysis of how local information ecologies emerge, a central contribution of our work is an accounting and theoretical grounding of resistance to these biases. The implication of what we find applies to both future CSCW research as well as programs seeking to support peer production of free and open content online. What future CSCW researchers studying digital cultures, as well as programs seeking to support and evaluate edit-a-thons and similar offline events, 
need to be aware of is these events are not simply about new contributions and contributors, but also represent sites of negotiation and contestation. Decisions regarding who participates, who is visible, what is counted as knowledge, what is recorded, and what is shown to others not only affect users of online peer production platforms, but almost everyone using the Internet today.

\section{ACKNOWLEDGMENTS}

This study was made possible by the facilitators who participated in this study. We acknowledge and thank our anonymous reviewers for their feedback on draft versions of this paper. Financial support for this work came from the School of Information and Library Science, University of North Carolina at Chapel Hill.

\section{REFERENCES}

[1] Alexa Internet Inc. 2020. wikipedia.org Competitive Analysis, Marketing Mix and Traffic - Alexa. https://www.alexa. com/siteinfo/wikipedia.org

[2] Sanghapali Aruna, Siko Bouterse, Az Causevic, Michael Connolly Miskwish, Persephone Hooper Lewis, Jake Orlowitz, Anasuya Sengupta, Belma Steta, and Maari Zwick-Maitreyi. 2018. Our Stories Our Knowledges: Part III Adding Our Knowledge to Wikipedia. https:/whoseknowledge.org/wp-content/uploads/2018/11/OurstoriesOurknowledgesPart3.pdf

[3] Eli Blevis, Susanne Bødker, John Flach, Jodi Forlizzi, Heekyoung Jung, Victor Kaptelinin, Bonnie Nardi, and Antonio Rizzo. 2015. Ecological Perspectives in HCI: Promise, Problems, and Potential. In Proceedings of the 33rd Annual ACM Conference Extended Abstracts on Human Factors in Computing Systems (CHI EA '15). Association for Computing Machinery, New York, NY, USA, 2401-2404. https://doi.org/10.1145/2702613.2702634

[4] Geoffrey C. Bowker. 2001. Bonnie Nardi and Vicki O’Day, Information Ecologies: Using Technology with Heart. Computer Supported Cooperative Work (CSCW) 10, 1 (March 2001), 143-145. https://doi.org/10.1023/A:1011277819050

[5] Virginia Braun and Victoria Clarke. 2006. Using thematic analysis in psychology. Qualitative Research in Psychology 3 , 2 (2006), 77-101. https://doi.org/10.1191/1478088706qp063oa

[6] Amy Bruckman, Kurt Luther, and Casey Fiesler. 2015. When Should We Use Real Names in Published Accounts of Internet Research? In Digital research confidential: The secrets of studying behavior online, Eszter Hargittai and Christian Sandvig (Eds.). MIT Press, Cambridge, MA, 243-258.

[7] Sheree Chang. 2016. A better view of Wikipedia content on Google - Wikimedia Blog. https://blog.wikimedia.org/ 2016/08/08/wikipedia-google-search/

[8] Kathy Charmaz. 2006. Constructing grounded theory. Sage Publications, London; Thousand Oaks, Calif.

[9] Anne Corden, Roy Sainsbury, University of York, and Social Policy Research Unit. 2006. Using verbatim quotations in reporting qualitative social research: researchers' views. University of York, York. OCLC: 171543970.

[10] Dallas Public Library. 2017. Dallas Public Library ArtAndFeminism 2017 - Programs \& Events Dashboard. https: //outreachdashboard.wmflabs.org/courses/Dallas_Public_Library/Dallas_Public_Library_ArtAndFeminism_2017

[11] Martin Dittus, Giovanni Quattrone, and Licia Capra. 2016. Social Contribution Settings and Newcomer Retention in Humanitarian Crowd Mapping. In Social Informatics, Emma Spiro and Yong-Yeol Ahn (Eds.). Springer International Publishing, Cham, 179-193.

[12] Samuel Dodson. 2019. Interacting with Heterogeneous Information Ecologies: Challenges and Opportunities for Students in Diverse and Distributed Learning Environments. In Proceedings of the 2019 Conference on Human Information Interaction and Retrieval (CHIIR '19). Association for Computing Machinery, New York, NY, USA, 445-448. https: //doi.org/10.1145/3295750.3298967

[13] Samir Elsharbaty. 2015. WikiCamps introduce young Armenians to Wikipedia. https://blog.wikimedia.org/2015/02/ 27/wikicamps-young-armenians-wikipedia/

[14] Siân Evans, Jacqueline Mabey, and Michael Mandiberg. 2015. Editing for Equality: The Outcomes of the Art+Feminism Wikipedia Edit-a-thons. Art Documentation: Journal of the Art Libraries Society of North America 34, 2 (Sept. 2015), 194-203. https://doi.org/10.1086/683380

[15] Rosta Farzan, Saiph Savage, and Claudia Flores Saviaga. 2016. Bring on Board New Enthusiasts! A Case Study of Impact of Wikipedia Art + Feminism Edit-A-Thon Events on Newcomers. In Social Informatics, Emma Spiro and Yong-Yeol Ahn (Eds.). Vol. 10046. Springer International Publishing, Cham, 24-40. https://doi.org/10.1007/978-3-319-47880-7_2

[16] Casey Fiesler, Shannon Morrison, R. Benjamin Shapiro, and Amy S. Bruckman. 2017. Growing Their Own: Legitimate Peripheral Participation for Computational Learning in an Online Fandom Community. In Proceedings of the 2017 ACM Conference on Computer Supported Cooperative Work and Social Computing (CSCW'17). Association for Computing 
Machinery, New York, NY, USA, 1375-1386. https://doi.org/10.1145/2998181.2998210 event-place: Portland, Oregon, USA.

[17] Kim Gile and Monika Sengul-Jones. 2018. How to Conduct a Wikipedia Edit-A-Thon. Computers in Libraries 38, 9 (Nov. 2018). http://www.infotoday.com/cilmag/nov18/Gile-Sengul-Jones--How-to-conduct-a-Wikipedia-Edit-aThon.shtml Computers in Libraries Magazine.

[18] Henry A. Giroux. 2000. PUBLIC PEDAGOGY AS CULTURAL POLITICS: STUART HALL AND THE CRISIS OF CULTURE. Cultural Studies 14, 2 (April 2000), 341-360. https://doi.org/10.1080/095023800334913

[19] Henry A. Giroux. 2004. Cultural studies, public pedagogy, and the responsibility of intellectuals. Communication and Critical/Cultural Studies 1, 1 (March 2004), 59-79. https://doi.org/10.1080/1479142042000180926

[20] Ruediger Glott, Philipp Schmidt, and Rishab Ghosh. 2010. Wikipedia survey-overview of results. United Nations University: Collaborative Creativity Group (March 2010), 1158-1178. https://web.archive.org/web/20131208221410/http: //wikipediasurvey.org/docs/Wikipedia_Overview_15March2010-FINAL.pdf

[21] Eduardo Graells-Garrido, Mounia Lalmas, and Filippo Menczer. 2015. First Women, Second Sex: Gender Bias in Wikipedia. In Proceedings of the 26th ACM Conference on Hypertext \& Social Media - HT '15. ACM Press, Guzelyurt, Northern Cyprus, 165-174. https://doi.org/10.1145/2700171.2791036

[22] Mark Graham, Bernie Hogan, Ralph K. Straumann, and Ahmed Medhat. 2014. Uneven Geographies of User-Generated Information: Patterns of Increasing Informational Poverty. Annals of the Association of American Geographers 104, 4 (July 2014), 746-764. https://doi.org/10.1080/00045608.2014.910087

[23] Aaron Halfaker, R. Stuart Geiger, Jonathan T. Morgan, and John Riedl. 2013. The Rise and Decline of an Open Collaboration System: How Wikipedia's Reaction to Popularity Is Causing Its Decline. American Behavioral Scientist 57, 5 (May 2013), 664-688. https://doi.org/10.1177/0002764212469365

[24] Benjamin Mako Hill and Aaron Shaw. 2013. The Wikipedia Gender Gap Revisited: Characterizing Survey Response Bias with Propensity Score Estimation. PLoS ONE 8, 6 (June 2013), e65782. https://doi.org/10.1371/journal.pone.0065782

[25] Nina Hood and Allison Littlejohn. 2018. Hacking History: Redressing Gender Inequities on Wikipedia Through an Editathon. The International Review of Research in Open and Distributed Learning 19, 5 (Nov. 2018). https: //doi.org/10.19173/irrodl.v19i5.3549

[26] Dorothy Howard and Lilly Irani. 2019. Ways of Knowing When Research Subjects Care. In Proceedings of the 2019 CHI Conference on Human Factors in Computing Systems - CHI '19. ACM Press, Glasgow, Scotland Uk, 1-16. https://doi.org/10.1145/3290605.3300327

[27] Taylor Hughes, Jeff Smith, and Alex Leavitt. 2018. Helping People Better Assess the Stories They See in News Feed with the Context Button. https://about.fb.com/news/2018/04/news-feed-fyi-more-context/

[28] Lorelei Lingard. 2019. Beyond the default colon: Effective use of quotes in qualitative research. Perspectives on Medical Education 8, 6 (Dec. 2019), 360-364. https://doi.org/10.1007/s40037-019-00550-7

[29] Allison Littlejohn, Nina Hood, Martin Rehm, Lou McGill, Bart Rienties, and Melissa Highton. 2019. Learning to become an online editor: the editathon as a learning environment. Interactive Learning Environments (July 2019), 1-14. https://doi.org/10.1080/10494820.2019.1625557

[30] Maggie MacAulay and Rebecca Visser. 2016. Editing Diversity In: Reading Diversity Discourses on Wikipedia. Ada: A fournal of Gender, New Media, and Technology 9 (May 2016). https://doi.org/10.7264/N36M3541

[31] Rachel M. Magee, Denise E. Agosto, and Andrea Forte. 2017. Four Factors That Regulate Teen Technology Use in Everyday Life. In Proceedings of the 2017 ACM Conference on Computer Supported Cooperative Work and Social Computing (CSCW '17). Association for Computing Machinery, New York, NY, USA, 511-522. https://doi.org/10.1145/ 2998181.2998310

[32] Katherine Maher. 2018. Wikipedia mirrors the world's gender biases, it doesn't cause them. https: //www.latimes.com/opinion/op-ed/la-oe-maher-wikipedia-gender-bias-20181018-story.html Archived at https://search.proquest.com/docview/2122754248.

[33] Jens-Erik Mai. 2016. Wikipedians' Knowledge and Moral Duties. Nordisk Tidsskrift for Informationsvidenskab og Kulturformidling 5, 1 (March 2016), 15-22. https://tidsskrift.dk/ntik/article/view/25879

[34] Sorin Adam Matei and Caius Dobrescu. 2010. Wikipedia's "Neutral Point of View": Settling Conflict through Ambiguity. The Information Society 27, 1 (Dec. 2010), 40-51. https://doi.org/10.1080/01972243.2011.534368

[35] Amanda Menking and Ingrid Erickson. 2015. The Heart Work of Wikipedia: Gendered, Emotional Labor in the World's Largest Online Encyclopedia. In Proceedings of the 33rd Annual ACM Conference on Human Factors in Computing Systems - CHI '15. ACM Press, Seoul, Republic of Korea, 207-210. https://doi.org/10.1145/2702123.2702514

[36] Dawn Nafus. 2012. 'Patches don't have gender': What is not open in open source software. New Media \& Society 14, 4 (June 2012), 669-683. https://doi.org/10.1177/1461444811422887

[37] Bonnie A Nardi and Vicki O’Day. 1999. Information ecologies: using technology with heart. MIT Press, Cambridge, Mass. 
[38] Lisa P. Nathan and Eric M. Meyers. 2016. Enriching Visions of Sustainability through Informal Public Pedagogies. Interactions 23, 5 (Aug. 2016), 54-57. https://doi.org/10.1145/2971484

[39] Oded Nov. 2007. What motivates Wikipedians? Commun. ACM 50, 11 (Nov. 2007), 60-64. https://doi.org/10.1145/ 1297797.1297798

[40] Chaim Noy. 2008. Sampling Knowledge: The Hermeneutics of Snowball Sampling in Qualitative Research. International Journal of Social Research Methodology 11, 4 (Oct. 2008), 327-344. https://doi.org/10.1080/13645570701401305

[41] Jude Ntabathia. 2019. Categories of Control and Visibility in Mapping Infrastructures. In Proceedings of the 2nd ACM SIGCAS Conference on Computing and Sustainable Societies (COMPASS '19). Association for Computing Machinery, New York, NY, USA, 174-183. https://doi.org/10.1145/3314344.3332494 event-place: Accra, Ghana.

[42] Leysia Palen, Robert Soden, T. Jennings Anderson, and Mario Barrenechea. 2015. Success \& Scale in a Data-Producing Organization: The Socio-Technical Evolution of OpenStreetMap in Response to Humanitarian Events. In Proceedings of the 33rd Annual ACM Conference on Human Factors in Computing Systems (CHI '15). Association for Computing Machinery, New York, NY, USA, 4113-4122. https://doi.org/10.1145/2702123.2702294 event-place: Seoul, Republic of Korea.

[43] Fran. Peavey. 1994. By life's grace: musings on the essence of social change. New Society Pub., Philadelphia, PA https://catalog.hathitrust.org/Record/002806954

[44] Eric Phetteplace. 2015. How Can Libraries Improve Wikipedia? Reference \& User Services Quarterly 55, 2 (2015), 109-112. https://www.jstor.org/stable/refuseserq.55.2.109

[45] Joseph M. Reagle. 2005. Is the Wikipedia Neutral? Cambridge. https://reagle.org/joseph/2005/06/neutrality.html

[46] Joanna Saad-Sulonen. 2010. EParticipation as an Information Ecology: A Micro-Scale Examination of Two Cases in Helsinki. In Proceedings of the 22nd Conference of the Computer-Human Interaction Special Interest Group of Australia on Computer-Human Interaction (OZCHI '10). Association for Computing Machinery, New York, NY, USA, 384-387. https://doi.org/10.1145/1952222.1952309

[47] Jennifer A. Sandlin, Michael P. O’Malley, and Jake Burdick. 2011. Mapping the Complexity of Public Pedagogy Scholarship: 1894-2010. Review of Educational Research 81, 3 (Sept. 2011), 338-375. https://doi.org/10.3102/0034654311413395

[48] Jennifer A. Sandlin, Brian D. Schultz, and Jake Burdick (Eds.). 2010. Handbook of public pedagogy: education and learning beyond schooling. Routledge, New York.

[49] Monika Sengul-Jones. 2017. Librarians Who Wikipedia: Tiffany Bailey, Dallas Public Library. https://www.webjunction. org/news/webjunction/librarians-wikipedia-tiffany.html

[50] Rose Sliger Krause, James Rosenzweig, and Paul Victor. 2017. Out of the Vault: Developing a Wikipedia Edit-a-thon to Enhance Public Programming for University Archives and Special Collections. Journal of Western Archives 8, 1 (Jan. 2017). https://digitalcommons.usu.edu/westernarchives/vol8/iss1/3

[51] Sara Snyder. 2018. Edit-a-Thons and Beyond. In Leveraging Wikipedia: connecting communities of knowledge, Merrilee Proffitt (Ed.). ALA Editions, Chicago, 119-132.

[52] Dario Taraborelli and Giovanni Luca Ciampaglia. 2010. Beyond Notability. Collective Deliberation on Content Inclusion in Wikipedia. In 2010 Fourth IEEE International Conference on Self-Adaptive and Self-Organizing Systems Workshop. IEEE, Budapest, TBD, Hungary, 122-125. https://doi.org/10.1109/SASOW.2010.26

[53] Nathan TeBlunthuis, Aaron Shaw, and Benjamin Mako Hill. 2018. Revisiting "The Rise and Decline" in a Population of Peer Production Projects. In Proceedings of the 2018 CHI Conference on Human Factors in Computing Systems (CHI '18). Association for Computing Machinery, New York, NY, USA, 1-7. https://doi.org/10.1145/3173574.3173929 event-place: Montreal QC, Canada.

[54] Erik H. Trainer, Chalalai Chaihirunkarn, Arun Kalyanasundaram, and James D. Herbsleb. 2014. Community Code Engagements: Summer of Code \& Hackathons for Community Building in Scientific Software. In Proceedings of the 18th International Conference on Supporting Group Work (GROUP '14). Association for Computing Machinery, New York, NY, USA, 111-121. https://doi.org/10.1145/2660398.2660420 event-place: Sanibel Island, Florida, USA.

[55] Päivi Tynjälä. 2008. Perspectives into learning at the workplace. Educational Research Review 3, 2 (Jan. 2008), 130-154. https://doi.org/10.1016/j.edurev.2007.12.001

[56] Claudia Wagner, David Garcia, Mohsen Jadidi, and Markus Strohmaier. 2015. It's a Man’s Wikipedia? Assessing Gender Inequality in an Online Encyclopedia. North America. https://www.aaai.org/ocs/index.php/ICWSM/ICWSM15/paper/ view/10585

[57] Claudia Wagner, Eduardo Graells-Garrido, David Garcia, and Filippo Menczer. 2016. Women through the glass ceiling: gender asymmetries in Wikipedia. EPf Data Science 5, 1 (Dec. 2016), 5. https://doi.org/10.1140/epjds/s13688-016-0066-4

[58] Wikimedia Foundation and Concept Hatchery. 2019. Wikimedia Movement Organizers: Understanding the People who Power the Movement. Technical Report. Wikimedia Foundation. https://upload.wikimedia.org/wikipedia/commons/8/ 8b/Wikimedia_Movement_Organizers_Study.pdf

[59] Wikimedia Foundation, Inc. 2015. Learning and Evaluation/Evaluation reports/2015/Editathons - Meta. https: //meta.wikimedia.org/wiki/Learning_and_Evaluation/Evaluation_reports/2015/Editathons 
[60] Wikipedia. 2019. Wikipedia:About. https://en.wikipedia.org/w/index.php?title=Wikipedia:About\&oldid=926297166 Page Version ID: 926297166.

[61] Wikipedia. 2019. Wikipedia:Neutral point of view. https://en.wikipedia.org/w/index.php?title=Wikipedia:Neutral_ point_of_view\&oldid=924980093 Page Version ID: 924980093.

[62] Sarah Wyer. 2017. Folk Networks, Cyberfeminism, and Information Activism in the Art+Feminism Wikipedia Edit-athon Series. Master's thesis. University of Oregon, Eugene, OR. https://search.proquest.com/docview/1948789837? accountid $=14244$

Received January 2020; revised June 2020; accepted July 2020 